\title{
ITACA PROTOCOL: A POSSIBLE PATH TO SUSTAINABILITY IN THE GOVERNANCE OF THE BUILDING PROCESS
}

\author{
GIUSEPPE IIRITANO ${ }^{1,2}$, GIOVANNA PETRUNGARO ${ }^{1}$, BARBARA CORASANITI ${ }^{1}$, \\ MASSIMILIANO BAGAGLI ${ }^{2,4}$, LORENZO FEDERICONI ${ }^{3}$ \& COSTANZO DI PERNA $^{4}$ \\ ${ }^{1}$ Department of Infrastructures, Public Works, Mobility, Italy \\ ${ }^{2}$ Institute for Transparency of Contracts and Environmental Compatibility (ITACA), Italy \\ ${ }^{3}$ Protection, Management and Planning of the Territory Service, Italy \\ ${ }^{4}$ Marche Polytechnic University (UNIVPM), Italy
}

\begin{abstract}
Pursuing and disseminating the principles of sustainable construction requires, at the highest levels, an overview of the issues affecting the area and a detailed analysis of the potential that some regulatory instruments offer. For these reasons, the governance of the territory must start from an accurate assessment of the objectives to be pursued and the careful choice of the means to do so. In Italy, Institute for Innovation and Transparency of Procurement and Environmental Compatibility (ITACA) has been promoting the principles underlying the sustainable development of the territory for over 20 years. The areas of action of the Institute are various and varied: drafting of tools and documents necessary for the evaluation of the sustainability of interventions, training of technicians and personnel who take part in the certification process, involvement of stakeholders and third parties and collaborations with national and international bodies. After the first approval of the ITACA protocol, which took place in 2004, the assessment tool has undergone numerous changes and evolutions until it was approved as UNI Practice in 2015. Now the UNI Reference Practice 13:2019 - Environmental sustainability in buildings Operational tools for the assessment of sustainability is a nationally recognized rating system and its use and dissemination throughout the territory is being promoted through specific training courses for experts and inspectors. These courses will also allow to obtain the certification of skills according to the ISO/IEC 17024 standard. The ITACA protocol, over the years after its first approval, has been applied by various Italian regions within their own regional legislative autonomy and therefore constitutes a real shared institutional and "public" protocol. The Institute is also focusing on the development of the "urban scale protocol", urban areas are in fact experiencing an unprecedented rate of population growth facing very complex environmental challenges.

Keywords: construction sustainability, rating tools, sustainability assessment.
\end{abstract}

\section{INTRODUCTION}

The term sustainability is very widespread today, but only recently it received the right connotation and is being used appropriately. The current urban and territorial planning tools follow guidelines that place sustainability as a postulate and as a fundamental criterion for guiding choices in the use of available resources. Although, as early as 1972, in the European Soil Charter, the Council of Europe stated that "soil is one of humanity's precious assets and is a limited resource that is easily destroyed" and that "Governments and administrative authorities they must rationally plan and manage the resources represented by the soil", only in the last twenty years has been developed an awareness of the fragility of the environment. The territorial governance system should consider the different meanings of the term "environment" (anthropic, ecological, landscape and naturalistic) and the environmental values of the territorial systems in order to implement a sectoral division of competences at various levels of scale. It is to respond to the need for specific tools for the design and assessment of environmental sustainability that today various ranking systems have spread nationally and internationally. In Italy, the most widespread are ITACA protocol, LEED, 
CasaClima, based on the analysis of requirements and the attribution of scores that take into account the performance of buildings in energy and environmental terms. Precisely by virtue of the adaptability and replicability of these methods, many regions in Italy have adopted and regulated these assessment tools within specific processes, to promote and disseminate the principles of environmental sustainability and provide technicians with guidelines for quality design. Several universities are actively engaged in improving calculation methodologies and continuously updating the results obtained.

\section{ITACA: INSTITUTE FOR INNOVATION AND TRANSPARENCY OF PROCUREMENT AND ENVIRONMENTAL COMPATIBILITY}

In 1996, in Italian regions founded the non-profit association called ITACA "Institute for transparency, updating and certification of contracts", with the aim of carrying out actions shared by the regional system and undertake, at national level, a common and shared path and to promote and guarantee an effective technical coordination between the regions and the autonomous provinces in order to ensure a better connection between the state, the local authorities and the national associations representing operators economic sector.

Since 2005, ITACA has adopted the new name of "Institute for innovation and transparency of procurement and environmental compatibility", underlining its commitment also in terms of issues relating to environmental sustainability.

The Institute operates on specific objectives of stimulation, coordination and harmonization in key sectors of the activity of the public administration, trying to enhance its autonomy and responsibility, and carries out its activity through technical tables constituted not only by regional experts, but also by representative state and local administrations and representative bodies of the sector categories. This work has allowed a broad and concrete discussion on issues identified from time to time as well as the exchange of knowledge and sharing of projects that can constitute hypotheses of socio-economic and environmental development for the country. The issues that the Institute deals with are: public procurement; job security; specifications and prices; contracts regional observers; regional aggregators; environmental training and sustainability.

Among the statutory purposes of ITACA, the issue of the quality of public procurement emerges substantially, both in reference to the planning, design and awarding phases, and to the execution, transparency and control phases of contracts. "Working groups" and technical tables have been set up for each area made up of managers, officials of the regions and autonomous provinces and experts in the sector, who carry out study, research and in-depth study of the subject, drafting of documents and guidelines to support the activities. Training is among the most important activities and is provided by the Institute on the basis of the most comprehensive programs and initiatives for stakeholders. The training offer, created by favoring the use of interactive and remote methodologies, is also modulated on the basis of the results of the study, research and experimentation activities developed by ITACA.

\subsection{The promoting committee of the ITACA protocol and environmental sustainability}

The promotion and dissemination of good practices for the environmental sustainability of buildings is one of the activities that have characterized the work of the Institute since its inception, assuming a significant role on the issues of environmental sustainability of buildings and on an urban scale. Topical issues increasingly at the center of European and international policies, related to the reduction of pollution, global warming, water consumption, energy efficiency, land protection and human health. 
In particular, ITACA supports national and regional policies through the development and management of environmental protocols that propose and evaluate project choices in line with and in compliance with new sustainability models. In the Interregional Working Group for Sustainable Construction, discussions on specialized issues are promoted with the representatives of state and local administrations and specific sector categories stakeholders. The aim is to exchange knowledge and share objectives. Within this working group has been developed the first version of ITACA protocol in 2004.

The protocol is an aid tool for the activity of designers, companies, public administration in control procedures, and customers. It is the reference tool of the national construction inspection system, accredited by ACCREDIA Technical Regulation 33-2013, which established the ITACA National Protocol Register (RNPI). The register verifies the conformity of projects and/or the construction of buildings according to the protocol. The managing body of the National Register is the promoting committee of the ITACA protocol set up by the ITACA board of directors in 2013 for the promotion and dissemination of the environmental sustainability of buildings.

The committee carries out its activities nationally and internationally by promoting the environmental sustainability of buildings, pursuing innovation processes through the implementation of the certification processes of environmental sustainability of buildings according to the UNI PdR13:19 standard; supporting research, training and development of good practices, looking for collaborations with research centers, universities and other subjects interested in sustainability, organizing conferences, seminars and any other training initiative, including the dissemination of educational and information materials. The general goal is to promote the culture of environmental sustainability. As part of its institutional activities, the promoting committee has established the national lists of experts and inspectors of the UNI PDR 13/19 and it has approved the regulations for training courses for technicians aiming to become expert and/or inspectors. The Polytechnic University of Marche, as part of a collaboration with the promoting committee, is developing a software for calculating the global sustainability score through the UNI 13/19 reference practice.

\subsection{The ITACA protocol and the UNI reference practices}

The ITACA protocol is, at national level, one of the most widespread tools for assessing the level of energy and environmental sustainability of buildings; as other rating systems allows to verify the environmental performance of a building from different points: human health, expenditure of energy, water and other resources; it also promotes the construction of increasingly innovative buildings and the use of sustainable materials produced with low energy consumption and able to guarantee high levels of comfort. The protocol gives an objective and comparable evaluation using indicators and verification methods compliant with the technical standards and national laws. The protocol must be understood as a versatile document having different purposes in relation to its different use: it is a tool to support planning for professionals, control and guidance for the public administration, to support the choice for the consumer, to enhance an investment for financial operators.

ITACA implemented the protocol as part of the Interregional Working Group for Sustainable Building established in 2001. The goal was to provide regions with tools to support territorial policies and to promote environmental sustainability in the construction sector which to date continues to be the sector with the highest energy consumption (about $40 \%$ of the total) which affects and determines the most unsustainability of our countries. Since the approval of the first version of the protocol, in 2004, this instrument has been adopted by many regions and municipal administrations in various initiatives aimed at 
promoting and encouraging sustainable construction through the approval of regional laws, building regulations, tenders, urban plans, etc. Its wide diffusion is due to the intrinsic versatility of the document; the protocol derives from the SBTool international evaluation model, developed as part of the Green Building Challenge research process. The contextualization of the international method to the Italian territory took into account national characteristics. The starting point for the definition of the evaluation system are:

- the determination of the areas of assessment and of greater environmental impact;

- the identification of criteria that make it possible to measure the environmental performance of the building in question;

- the definition of reference performance (benchmark) considered the national and international legislation in force with which to compare those of the building for the purpose of assigning a score

- the attribution of weight to the criteria that determine its importance;

- the final aggregation of scores to determine the final synthetic score that defines the degree of improvement of the overall performance compared to the standard level.

This articulation determines the hierarchical structure of the protocol divided into areas, categories and evaluation criteria. The evaluation areas, which are the macro themes that determine the sustainability characteristics of the intervention, are: site quality, resource consumption, environmental loads, indoor environmental quality and service quality. With reference to the context and location of the building, the tool adapts by allowing the exclusion from the global system of criteria whose indicators cannot be evaluated due to the intrinsic characteristics of the building or the place of intervention. The evaluation criteria for calculating the performance score are organized in "criterion cards" and are grouped by reference category. The output of the activity conducted for the calculation of the performance score is an "evaluation report", carried out on a single building and its external area of relevance, containing the results of the evaluation with respect to the set of criteria taken into consideration. Since 2004, versions of the protocol for the evaluation of residential, commercial, office, industrial and school buildings subject to new construction or renovation have been approved.

In 2014, the 2011 residential ITACA protocol was replaced with the new UNI/PdR 13: 2015 reference practice "Environmental sustainability in buildings - Operational tools for assessing sustainability", created within a specific ITACA-UNI technical table. The document was then updated and published in July 2019 as UNI/PDR 13/19. The practice, which maintains the same calculation methodology through its hierarchical structure, allows the evaluation of new and renovated buildings and it is divided into three sections: Section 0 is about general framework and methodological principles; Section 1 and Section 2 which specify the criteria for the assessment of environmental sustainability and the calculation of the performance score of buildings for residential and non-residential use (for offices, commercial, school, industrial and hospitality). The update of the document in 2019 took into account the approval of the Ministerial Decree (DM) 11 October 2017 which contains the "Minimum Environmental Criteria (CAM) for the award of design services and works for the new construction, renovation and maintenance of public buildings" trying to standardize the criteria indicators to the reference benchmarks of the decree.

\subsection{The urban scale ITACA protocol}

Urban regeneration is commonly defined as a set of actions aimed at the recovery and redevelopment of an urban space, a process based on the environmental sustainability of the 
recovery interventions at the level of infrastructures and services, limiting land consumption and aiming at improving quality. of life in the social, economic and environmental spheres. Since 2013, the ITACA board of directors has welcomed these stimuli and expanded the assessment scale of the building's environmental sustainability to the urban scale, establishing an interregional working group dedicated to "environmental sustainability on an urban scale". A first version of the ITACA protocol at urban scale was approved in December 2016. It is configured as an evaluation tool capable of measuring the level of sustainability of interventions in the urban environment: from the block to the city, aimed at both public, and to operators involved in the development or transformation of urban areas. A very open and flexible tool, potentially usable on areas of application at various scales (isolated, sector, neighborhood), for the evaluation of projects (masterplan) or urban plans to be applied both in the design and monitoring phase.

\section{REGIONAL CERTIFICATION SYSTEMS}

Many Italian regions have adopted ITACA protocol as environmental sustainability assessment tool. Fig. 1 shows the overall situation of the regions using, having used or about to use ITACA protocol. At present they are 13 out of 20.

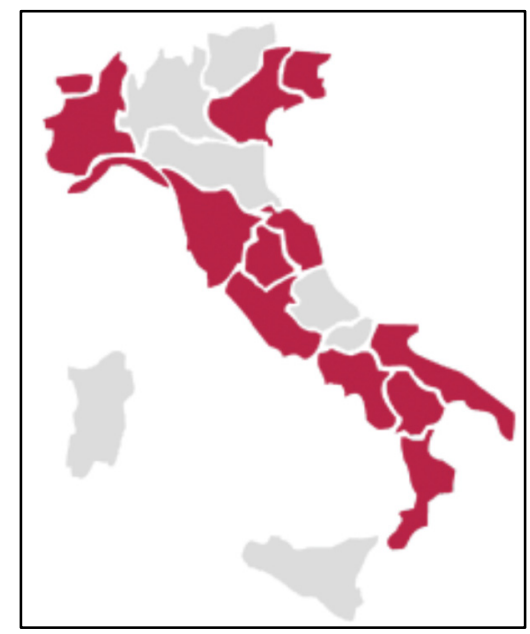

Figure 1: Regions using, having used or about to use ITACA protocol.

Three different levels of use of the regional protocols can be identified: a zero level for regions not having implemented any legal act in order to create a complex of procedures and uses of the protocol. A first level is characterised by regions having implemented some legal act and some procedures but with a small number of buildings going through the process of evaluation. A second level is identified by regions able to promote the evaluation process and with a considerable number of buildings being assessed. These considerations on different levels of use are related to the present situation but things can evolve and some regions could change their status. For example, the Tuscany region is in the process of getting legal approval of the regional law implementing the evaluation process and for these reasons is included in the level 1; it is likely for Tuscany to skip quickly to a higher level once this step will be completed. Table 1 summarises the various levels of use of regional protocols; Sections 3.1-3.6 show the main regional legal acts and uses of regional protocols. 
Table 1: Summary of the various levels of use of regional protocols.

\begin{tabular}{|l|l|}
\hline Regions & Level \\
\hline $\begin{array}{l}\text { Piedmont, Umbria, Marche, Apulia, } \\
\text { Calabria }\end{array}$ & $\begin{array}{l}\text { Level 2: Ability to promote the evaluation process } \\
\text { and with a considerable number of assessed } \\
\text { buildings }\end{array}$ \\
\hline $\begin{array}{l}\text { Aosta Valley, Liguria, Veneto, } \\
\text { Friuli, Lazio, Tuscany, Campania, } \\
\text { Basilicata }\end{array}$ & $\begin{array}{l}\text { Level 1: Implementation of some legal act and } \\
\text { some procedures but with a small number of } \\
\text { assessed buildings }\end{array}$ \\
\hline $\begin{array}{l}\text { Lombardy, Trentino South Tyrol, } \\
\text { Emilia Romagna, Abruzzo, Molise, } \\
\text { Sicily, Sardinia }\end{array}$ & Level 0: Not legal act and procedures approved \\
\hline
\end{tabular}

\subsection{Apulia region}

Since 2008 with the Regional Law n.13 Apulia region has adopted ITACA protocol a regional version (Apulia ITACA protocol). The regional version has the same areas of evaluation of the national version but a lower number of criteria. The Regional Law n.13, with the aim of encouraging the construction of sustainable buildings and good construction practices, has introduced some incentives (volume increases and tax relief) linked to the achievement of good Apulia ITACA protocol overall scores. Sustainable building interventions covered by the regional law must involve the entire building and belong to one of the following types:

- implementation plans;

- new building interventions including extensions of existing buildings (in this case the assessment is extended to the entire building);

- $\quad$ building renovation;

- demolition and reconstruction.

During 2017 Apulia region has updated the regional version with two different subversions (one for residential buildings and the other one for not residential buildings). Apart from the regional protocol Apulia region has put great emphasis on training and qualification of technicians implementing a considerable number of courses: final result has been the creation of a list of technicians named "Apulia ITACA protocol experts" who are in title of preparing the documentation for the evaluation. This effort has given remarkable results and, as average, about one hundred buildings is being assessed every year.

\subsection{Calabria region}

The Calabria region, starting from 2015, has embarked on a virtuous path that has resulted in a program aimed at creating an organic system of procedures aimed at sustainable development of the territory. The implementation of the provisions contained in Regional Law no. 41/2011 "Standards for sustainable living", which aspires to promote and encourage environmental sustainability and energy saving both in territorial and urban transformations, and in the construction of public and private building works, had now become an obligatory step to start the sustainability path required by the European Community and by the 2030 Agenda. 
In 2016 the D.G.R. n. 521, approved the regulations and the technical regulations for the implementation of the L.R. nf. 41/2011 which implemented the ITACA protocol for residential and school buildings of the Calabria region and defines the fundamental aspects of the certification process. In November 2017, the ITACA protocol for public buildings was also implemented. The regional ITACA protocol for residential buildings was developed as part of a university project taking into account the climatic-environmental characteristics and criticalities of the Calabrian territory and there are new indicators and criteria. The regional protocols derive from UNI/PdR 13: 2015 and have a variable number of criteria between 33 and 36.

The technical regulation requires obtaining an environmental sustainability certificate, with a minimum score of 1 , for all interventions carried out with public contributions and which intend to make use of concessions and incentives. The Calabria region, since November 2016, requires as a requirement for participation in the notices for the granting of funding and contributions, the preparation of an assessment report of the level of environmental sustainability of the intervention that is proposed for selection. The value declared in the application phase must then be confirmed in the subsequent phases with the final obtaining of the environmental sustainability certificate. In the Regional Law n. 21 of 2010 and subsequent amendments, the so-called house plan, a volumetric premium is provided according to the level of sustainability achieved by the intervention.

The region has also defined the figures who, in various capacities, play fundamental roles in the certification process. The accreditation system of the Calabria region provides that the environmental sustainability assessment of the intervention can only be carried out by the evaluators, or by technicians enrolled in a special regional list: "List of ITACA Protocol Experts" which can be accessed by attending specific courses. Currently in Calabria several hundred technicians are registered on the list. Since February 2020, the region has adopted the UNI/PdR 13:2019 Training Regulations for Experts approved by the promoting committee and the national list established.

In May 2019, the Calabria region hosted, in the splendid landscape of Scilla, one of the international conferences of the SBE (sustainable built environment) cycle. The focus of the SBE19 Scilla conference was focused on policies, programs and action plans aimed at improving the sustainability of the built environment and representatives of the United Nations Agency for the Mediterranean Sustainable Development Program (UNEP Mediterranean Action Plan Coordinating Unit), of the Government of Catalonia, of the European Energy Cities network, of the European Sustainable Cities network, with the awarding of the best experiences, of the European Commission, Directorate General for the Environment.

\subsection{Piedmont region}

Piedmont region has been the first to use the protocol as tool for assessing buildings and has started since the early 2000s applying it to some urban regeneration programs called Neighborhood Contracts 2. Since these first experiences Piedmont region has signed an agreement (three times resigned so far) with ITACA to get direct support. The Piedmont region has developed and implemented regional version with respect to the various building types and territorial peculiarities. The protocol has been experimented in different areas of intervention such as public social housing, private housing, commercial building, school and public bodies buildings. At present the current regional version in force is the third one and it has been implemented in 2018. The Piedmont region, as partner, is involved in several European projects with the aim of promoting the level of sustainability of the built 
environment both on a neighborhood and territorial scale; in all these projects the regional version is used. During the years Piedmont region has used ITACA protocol in many regional invitations to tender, it is worthy to remind some of them:

- Urban redevelopment programs for sustainable rental housing;

- Housing Program: 10,000 housing units by 2012;

- Invitations to tender for school buildings;

- Calls POR FESR 2014/2020;

- Invitations to tender for commercial buildings.

As happened in other regions also Piedmont region has a regional version with the same areas of evaluation of the national version but with a lower number of criteria. Similarly to other regions also Piedmont region has put great effort on training and qualification of technicians implementing a remarkable number of courses leading to a regional list of experts.

\subsection{Lazio region}

In Lazio the first edition of the ITACA protocol is from 2008 with the first regional version for residential buildings. Two years later the non-residential buildings version completed the possibility of using the protocol; both of them have been updated in 2015. Although several regions have developed some kind of tool to facilitate calculations when operating with the protocol Lazio region in 2015 was the first to launch a software. Such a software, free and downloading from the Lazio region internet site, allowed technicians to design buildings taking into account the protocol and, at same time, it helped the public administration in the control procedures. After this first experience in Lazio region the idea of developing some software able to make many of the calculations required by the criteria of the protocol, as a consequence of their connection to a considerable number of technical standards, has become a goal for ITACA at a national level and something is going to happen in a near future. As in other regions the local version has a lower number of criteria and it has been used in some invitations to tender as an instrument to assess projects.

\subsection{Umbria region}

The current versions of the technical regulations for the evaluation of the environmental sustainability characteristics of buildings are the instruments used by Umbria region to revise the certification criteria, making them more applicable. The regulatory framework governing the assessment has been introduced by Regional Law 17/2008 and it has already been completed with the publication of the first version of the criteria for residential buildings (DGR. n. 581/09), followed by the second (DGR. n. 1322/09) and the third one (DGR. n. 130/13). Currently, the regulatory framework is represented by the fourth version for residential buildings (DGR n. 743/18), the second version for office buildings (DGR 503/19 replacing DGR n. 1079/13), the first version for school buildings (DGR n. 844/19) and the rules for mixed-use buildings (DGR 480/19 replacing DGR n. 953/13). In the meantime Regional Law 1/15 has repealed. R.L. 17/08 and 13/09, maintaining the approach given by the previous rules, including possible bonuses deriving from Sustainability Certification of buildings. The regional version of the protocol includes a lower number of criteria and also in this case has been used in some invitations to tender as an instrument to assess projects. Umbria region is one of the smallest Italian region but it has achieved remarkable numbers in terms of assessed buildings: as average every year around 150 projects are being evaluated. 


\subsection{Marche region}

Since 2003, Marche region approved the simplified system of evaluation of eco-sustainable building projects, according to a performance method related to the international system "Green building challenge", based on the identification of requirements to meet grouped by evaluation areas ( 28 requirement sheets).

In 2005, a summarized section of the protocol (15 sheet requirement protocol) was updated to comply with current legislation. Regional Law no. 14/2008 was issued to make the "Protocol" operational and develop a set of regulatory and technical tools.

The law defines the certification of sustainability of buildings based on the principles of the ITACA protocol, the instrument to promote and incentive actions for the sustainability of buildings, to be implemented through a series of economic aid and incentives.

The main section of the law concerns the system of certification of the sustainability of buildings and the technical modalities of awareness and control of the level of performance reached. Later, the region set out the procedures and controls, the accreditation of professionals qualified for certification, and the acquisition of the certificate and defined the general principles of the technical procedures for assessing the sustainability of buildings, in accordance with the principles of the GB Tool, based on the methodology adopted by the ITACA protocol. These tools define the structure of the technical specification, the technical tool at the basis of the building certification. Alongside these are the guidelines, a sort of explanatory manual and guidance also containing practical examples that illustrate in detail how to achieve the chosen levels of performance and a computerized system that makes it easier for users (designers and certifiers) to fill in the forms contained in the technical specifications. The region, in addition to the checking and updating of the system, together with the municipalities, carries out sample checks and controls on buildings and projects to be certified.

The law is based on a hypothesis of voluntary integration of the mandatory certification of energy performance resulting from Article 6 of Legislative Decree 192/2005, which applies to broader environmental performance, aiming to create a sort of "virtuous competition" between owners, builders, designers.

In 2011 the system and procedures for energy and environmental certification of buildings, the criteria and procedures for the training and accreditation of qualified bodies for the issue of certification and the criteria and procedures for the allocation of subsidies and the adoption of incentives were approved. A regional register of certifiers of the environmental energy sustainability of buildings has also been established. The register is updated every 6 months and currently has 621 members.

In 2016, the Guidelines for the environmental energy assessment of residential buildings were replaced with the reference practice UNI/PdR 13:2015, which already contained the aforementioned new calculation methodologies.

Marche region adopted the UNI PdR 13:2019 Reference Practice in 2021, in addition, the accreditation system was updated and the regulations for training courses for Experts/Inspectors were approved.

\section{PILOT PROJECTS: EXPERIENCE OF THE MARCHE REGION}

The incentives set out by LR n.14/2008, (reduction of secondary urbanization charges, construction costs and volumetric increases), are applied on new buildings according to the score obtained by the application of Protocol ITACA Marche. In 2009, the Marche region financed certified sustainable building projects by launching a call for tenders for $€ 100,000.00$ for companies, real estate companies, cooperatives, construction companies and 
private citizens for residential building projects of high environmental quality, to be certified according to the ITACA protocol - Marche. Interventions could concern both new constructions and recoveries, as well as already realized works if documented. Interventions should obtain an overall score lower than 1 of the ITACA protocol.

The general objective is to improve the energy and environmental quality of residential buildings starting from a substantial reduction in energy consumption, expanding the theme to water saving, quality of materials, indoor comfort. The specific objective is to encourage and monitor, also in order to make any corrective improvements, the sustainability certification system of buildings, especially in its initial application.

In 2021, a framework agreement between the Marche region, UNIVPM (Marche Polytechnic University) and ITACA to promote, develop and consolidate opportunities and initiatives for collaboration in the field of environmental sustainability of buildings was approved. It promotes research activities, joint participation in regional, national, European and international calls and research programs, with particular attention to the Framework Programmes of the European Commission, technical and scientific consulting activities, promotion of dissemination activities of scientific and technological culture on the territory. Moreover the council approved an implementing agreement for the application and dissemination of the UNI/PdR 13:2019 on the regional territory, which provides for the launch of training, communication and dissemination activities on issues of environmental sustainability of buildings, the development and updating of an IT tool to support professionals for the application of the ITACA protocol and the assignment of a performance score, the launch of experimentation activities of the ITACA protocol on an urban scale with real cases, the collaboration in the activities of training courses for experts and inspectors ITACA protocol, recognized by the promoter committee, the start of implementation and updating activities of the UNI/PdR 13:2019.

The national legislation on the Piano Casa (house plan) foresees interventions of enlargement, demolition and reconstruction on residential buildings or buildings of different destination, to be carried out as a derogation to urban planning instruments and building regulations in force.

Regional Law 22/2009 aims to the improvement of the quality of buildings in terms of seismic safety and energy efficiency. Marche region is currently participating as a partner in the Interreg Europe LC District project whose main aim is to create low carbon districts. An action plan is foreseen within the implementation of the project activities. One of the actions includes the design of low-carbon districts in the Marche region using a methodology that combines the design to environmental energy certification through the application of the ITACA protocol both at building and urban scale. This approach will ensure projects with high environmental energy performance resulting in a low impact at the level of $\mathrm{CO}_{2}$ production. This process has involved both the interregional partnership and local stakeholders with particular reference to the municipalities involved. Through the collaboration with the Polytechnic University of Marche foreseen by the framework agreement, curricular and extracurricular internships will be activated at the Marche region premises for experimental applications of the two protocols at urban and building scale in different contexts of the regional territory.

\section{CONCLUSIONS}

In recent years, the dissemination and promotion of the principles of environmental sustainability carried out by ITACA has led to the achievement of significant results:

- disseminating the principles of sustainable construction among stakeholders; 
- developing the UNI PDR 13/2019, the ITACA protocol at urban scale and the operational tool;

- legal acts from various regions implementing assessment procedures;

- thousands of buildings certified or in the process of certification;

- training of technicians and personnel who take part in the certification process.

On the basis of what has been described in the previous paragraphs, it is easy to glimpse future developments and possibilities:

- nationally and internationally dissemination of principles and tools for the design and assessment of the environmental sustainability of buildings;

- further developments and updates of UNI PDR 13/09, urban-scale protocol and operational tools;

- participation in national and international projects and initiatives on environmental sustainability

- $\quad$ partnership with entities interested in building sustainability;

- capillary training involving universities and other stakeholders.

\section{REFERENCES}

[1] Istituto per l'innovazione e Trasparenzadegli Appalti e la Compatibilità Ambiental (ITACA). http://www.itaca.org. Accessed on 3 April 2017.

[2] I criteri ambientali minimi. https://www.mite.gov.it/pagina/i-criteri-ambientaliminimi.

[3] Sustainable Building Program of the Calabria Region. Sustainable Built Environment Conference Series (SBE 2019) Scilla. ISBN 9791220057387.

[4] Communication from the Commission to the Council and the European Parliament, the Economic and Social Committee and the Committee of the Regions - Towards a thematic strategy for soil protection (COM(2002) 179). https://eur-lex.europa.eu/legalcontent/it/ALL/?uri=CELEX:52002DC0179. Accessed 17 April 2002.

[5] Mattoni, B., Bisegna, F., Evangelisti, L., Guattari, C. \& Asdrubali, F., Influence of LCA procedure on the green building rating tools outcomes. IOP Conference Series: Materials Science and Engineering, 2019.

[6] Principi, P., Catalino, S. \& Fioretti, R., The contribution of the ITACA Protocol in the control of the environmental quality in residential buildings and the subsequent contribution to the adaptation to climatic change. Energy Procedia, 2015.

[7] Baglivo, C., Congedo, P.M. \& Fazio, A., Multi-criteria optimization analysis of external walls according to ITACA protocol for zero energy buildings in the mediterranean climate. Building and Environment, 2014.

[8] Moro, A., Catalino, S., Rizzuto, G. \& Tirelli, T., ITACA: A GBC based environmental performance assessment tool for the public administration in Italy. The 2005 World Sustainable Building Conference, SB05Tokyo, pp. 1844-1847, 2005.

[9] WCED - World Commission on Environment and Development, Report of the World Commission on Environment and Development: Our common future. 1987. https://sustainabledevelopment.un.org/content/documents/5987our-commonfuture.pdf.

[10] United Nations, Transforming our World: The 2030 Agenda for Sustainable Development, 2015. https://sustainabledevelopment.un.org/content/documents/ $21252030 \% 20$ Agenda\%20for\%20Sustainable\%20Development $\% 20$ web.pdf. 
[11] United Nations, Global indicator framework for the Sustainable Development Goals and targets of the 2030 Agenda for Sustainable Development, 2018.

https://unstats.un.org/sdgs/indicators/Global\%20Indicator\%20Framework\%20after\% 20refinement_Eng.pdf.

[12] Ministero dell'Ambiente e della Tutela del Territorio e del Mare, Strategia Nazionale per lo Sviluppo Sostenibile, 2017. https:/www.minambiente.it/sites/default/files/ archivio_immagini/Galletti/Comunicati/snsvs_ottobre2017.pdf.

[13] Baur, A.H., Thess, M., Kleinschmit, B. \& Creutzig, F., Urban climate change mitigation in Europe: Looking at and beyond the role of population density. Journal of Urban Planning and Development, 140(1), 2014.

DOI: 10.1061/(ASCE)UP.1943-5444.0000165.

[14] United Nations Framework Convention on Climate Change, Paris Agreement, 2015. https://unfecc.int/. DOI: 10.2495/SC140832.

[15] Regione Calabria, Protocollo ITACA, Regione Calabria, Edifici Pubblici, 2017. itaca.calabria.iisbeitalia.org/sites/default/files/Protocollo_ITACA_Reg.Calabria_Ed.P ubblici_2017.pdf.

[16] Regione Calabria, Protocollo ITACA, Regione Calabria, Edifici Pubblici, 2017. http://itaca.calabria.iisbeitalia.org/sites/default/files/Protocollo_ITACA_Reg.Calabria Ed.Pubblici_2017.pdf.

[17] Petrungaro, G. \& Corasaniti, B., Sustainable building program of the Calabria region. Sustainable Built Environment Conference, 16-17 May, Scilla, Italy, 2019.

[18] Petrungaro, G. \& Corasaniti, B., Sustainable building program of the Calabria region. Sustainable Built Environment Conference, Scilla, Italy, 2019. www.sbe19scilla.org/index.php/sbe19-proceedingsRegioneCalabria.

[19] Delibera di Giunta Regionale n. 300 dell'1.7.2019, Atto di indirizzo per la definizione del Progetto Strategico "SCUOLA SICURA", finalizzato all'aggiornamento del Piano regionale triennale 2018-2020 in materia di edilizia scolastica.

[20] Petrungaro, G., Iiritano, G., Caruso, M., Di Ludovico, M. \& Prota, A., Una procedura per la valutazione speditiva del rischio sismico degli edifici scolastici. L'applicazione agli edifici scolastici della Calabria. XVIII Convegno ANIDIS L'ingegneria Sismica in Italia. Ascoli Piceno 15-19 September, 2019. 